\title{
"Elucidating the Problem of Pier Abutment through the Use of a Fixed Movable Prosthesis - A Clinical Case Report”
}

\author{
Khurshid Mattoo ${ }^{1, *}$, Anchal Brar ${ }^{2}$, Roma Goswami ${ }^{3}$ \\ ${ }^{1}$ Prosthodontics, College of dental sciences, Jazan University, KSA \\ ${ }^{2}$ Prosthodontics, Kalka dental college, Uttar Pradesh, India \\ ${ }^{3}$ Prosthodontics, Subharti dental college, Meerut, India \\ *Corresponding author: drkamattoo@rediffmail.com
}

Received October 30, 2014; Revised November 22, 2014; Accepted November 27, 2014

\begin{abstract}
Many times a dental practitioner comes across a situation where his clinical dexterity and knowledge can make the difference between a patient being delivered a removable or a fixed prosthesis. One such clinical situation is existence of a pier abutment in between two edentulous areas. Managing such a partial edentulous situation with a fixed partial denture can be successfully accomplished by those who understand basic principles of using a non-rigid connector, custom made in the laboratory. Clinical application of mandibular movements on the occlusal anatomy of artificial crowns is an essential component in such cases besides adequate education and motivation of the patient. This article in the form of a clinical case report describes the management of pier abutment case over a period of 5 years with a fixed movable prosthesis. A custom made design in the laboratory allows the pier abutment to support two different prostheses on either side, without undergoing any retentive or biological failure of the abutment. Moreover the flexible design also allows the patient to benefit from fixed prosthesis rather than a conventional removable prosthesis.
\end{abstract}

Keywords: non-rigid connectors, semi precision attachment, fixed partial denture, mandibular movements

Cite This Article: Khurshid Mattoo, Anchal Brar, and Roma Goswami, “"Elucidating the Problem of Pier Abutment through the Use of a Fixed Movable Prosthesis - A Clinical Case Report”." International Journal of Dental Sciences and Research, vol. 2, no. 6 (2014): 154-157. doi: 10.12691/ijdsr-2-6-8.

\section{Introduction}

Selecting an abutment that will lead to success of tooth supported prosthesis requires receptive, sensitive and insightful diagnostic ability. A thorough knowledge of dental anatomy, dental ceramics, the chemistry and physics of dental materials, metallurgy, periodontics, phonetics, physiology, radiology and the mechanics of oral function is fundamental to fulfill the definite rules of treatment planning. [1] At the same time, an understanding of the favorable indications and reasonable limitations of abutments for fixed partial dentures is essential. [2] Attempts have been made to establish objective standards for abutment evaluation [3,4] but have not presented evidence based criteria. The crown-to-root ratio (CRR) is one of the primary variables in the evaluation of the suitability of a tooth as an abutment for a fixed or removable partial denture. [3,4,5] However, abutment mobility, alveolar bone support, root configuration and angulation, opposing occlusion, pulpal condition, presence of endodontic treatment, and the remaining tooth structure have also been cited as predictors for abutment longevity $[7,8]$.

Besides fulfilling these criteria, there are partial dentulous situations where an abutment is situated in between the two critical edentulous areas. Such abutments have been called as a pier abutment. Planning a fixed partial denture that has rigid connectors for a pier abutment result in debonding of the anterior abutment [9] or teetering movement [10] wherein middle retainer acts as a fulcrum (Figure 1). This problem can be easily avoided with the use of a non-rigid connector (Figure 2) [11].

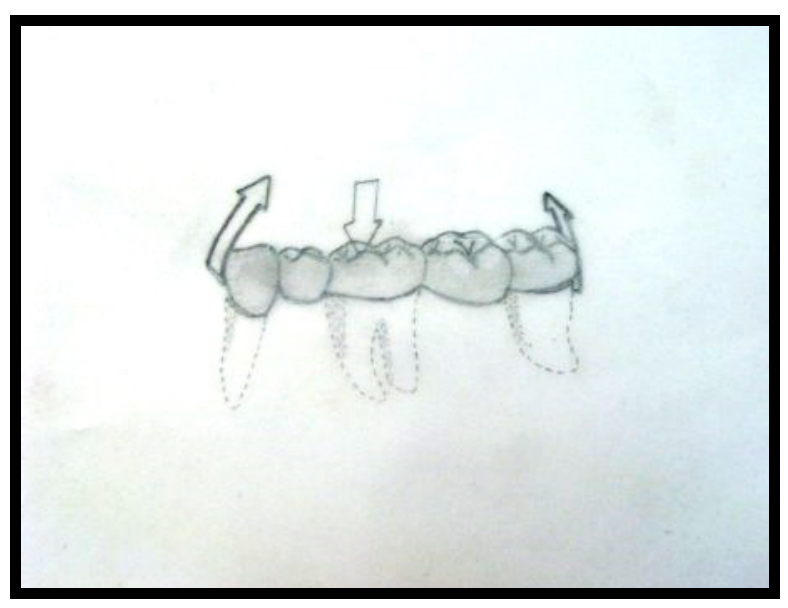

Figure 1. Decementation of a fixed partial denture due to use of rigid connector in a pier abutment situation 
Placement of non-rigid connector has been advocated by many and different authors have suggested different locations like terminal retainer, [10] distal of the pier and one more at distal of anterior retainer [11].

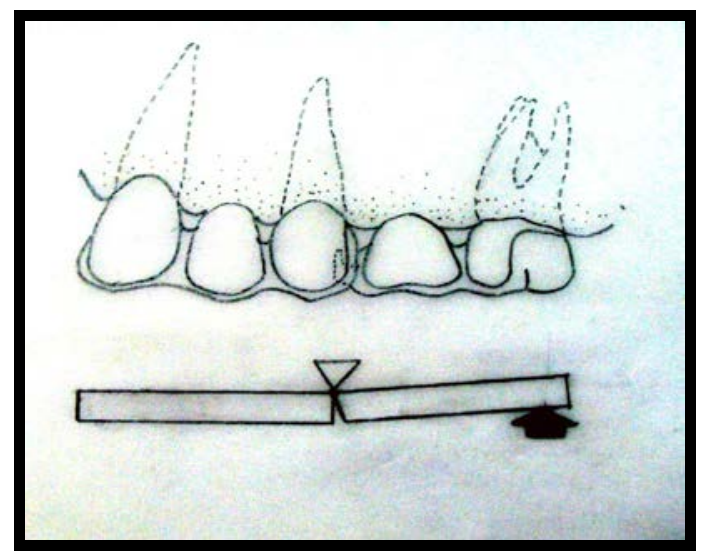

Figure 2. Stress breaking effect with use of non-rigid connector

Some have recommended non usage of non-rigid connectors, [12] while many other authors also have recommended that a stress breaking mechanical union of pontic and retainer $[14,15]$

Though there are numerous attachments that can provide the required stress breaking effect in a long span bridge supported in the middle by a pier abutment, this article describes a simple and innovative method of fabricating a dowel type semi precision attachment by utilizing the design of an intra-coronal semi precision rest. It provides the clinician with the benefits of being less costly, ease of fabrication and less tooth reduction.

\section{Clinical Case Report}

A female patient, aged 42 years, came to the department of Prosthodontics, with a chief complaint of difficulty in mastication since last 2 years due to missing maxillary rear teeth, lost due to tooth decay. The sequence of loss of teeth was right second molar, followed by left first molar and then the right second premolar. A detailed medical, dental, social, climacteric and diet history was obtained. Inspection of the oral cavity revealed good oral hygiene with a class I molar relationship. The edentulous areas were examined for severity of bone loss. Maxillary left first molar acted as a pier abutment. Palpation of the teeth and in particular the potential abutments, did not reveal any sign or symptom of periodontal disease. Percussion of the teeth also did not reveal any significant abnormality of pulp or periapical area. Evaluation of the functional occlusion revealed presence of wear facets in relation to maxillary canines. Occlusal examination revealed a mutually protected occlusion with canine's discluding the posteriors and anteriors in lateral excursions. Individual examination of the potential abutments on both sides revealed an adequate crown length. Radiographic examination revealed an adequate crown root ratio, favorable root morphology, healthy periodontal ligament space, positive long axis relationship, favorable gingival margin location, ideal occlusal morphology, occlusal plane and no evidence of any periapical or periodontal pathology (Figure 3). Upon analysis of the pericemental areas of all the abutments, a tentative treatment plan that included a fixed fixed (rigid) prosthesis for restoring the missing right first molar and a fixed movable prosthesis for the missing left second premolar and left second molar. Other treatment modalities that were discussed with the patient for management of pier abutment included single tooth implant for each edentulous space or a combination of single tooth implant and a fixed fixed prosthesis or a resin bonded prosthesis or a removable partial denture.

After making preliminary impressions of maxillary and mandibular partially edentulous arches with irreversible hydrocolloid (Thixotropic, Zhermach, Italy), the impressions were poured with Type III dental stone (Elite Model; Zhermack, Badia Polesine, Rovigo, Italy). Centric and protrusive interocclusal records were made using interocclusal wax records (Metrowax; Metrodent Ltd, Huddersfield, West Yorkshire, UK). The diagnostic casts were mounted on a Hanau Widevue semi adjustable articulator (Waterpik, Ft Collins, CO, USA) using a Hanau spring bow. The articulator was programmed and the entire diagnosis and fabrication of prosthesis was done on the programmed articulator.

Prosthetic rehabilitation was carried in two stages. In the first stage the abutments on the right side were prepared to receive a porcelain fused to metal, fixed fixed prosthesis with buccal facing and occlusal metal. In the second stage, all the planned abutments for fixed movable prosthesis were prepared. The posterior segment was fabricated first which contained a dove tail design for the anterior part of the prosthesis (Figure 4). A box preparation was made on the mesial aspect of the retainer in relation to the pier abutment during wax up and the two separate wax patterns were cast separately. After cementing the posterior part of the fixed movable prosthesis first, a temporary restoration was given in relation to the anterior part (Figure 5).

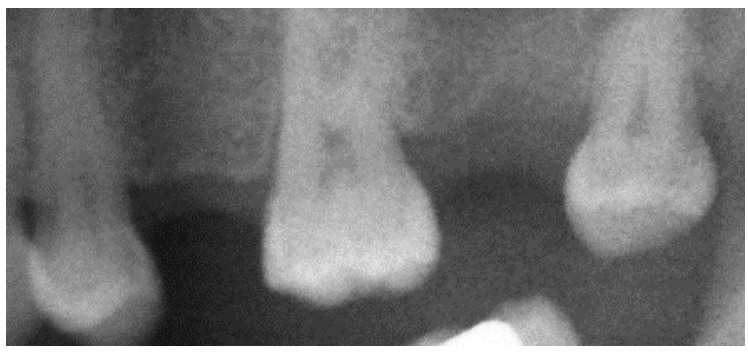

Figure 3. Preoperative radiograph showing the position of the pier abutment

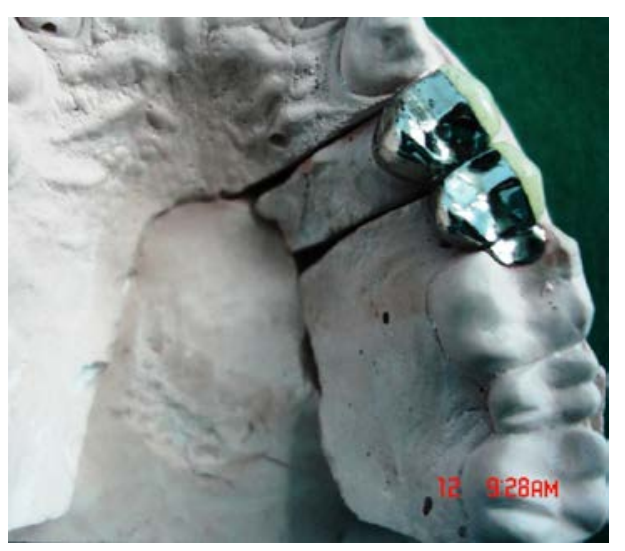

Figure 4. Fabrication of anterior fixed partial denture with a semi rigid connector on the distal aspect of the pontic 


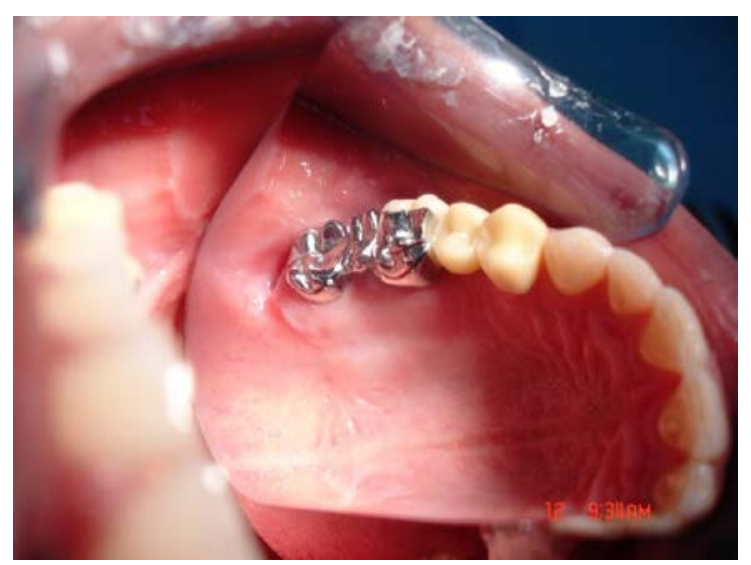

Figure 5. Temporization of a fixed movable prosthesis

In the next stage the anterior component of the fixed movable prosthesis was cemented after careful evaluation for fit and marginal integrity (Figure 6). The patient was given instructions regarding maintenance and was put on a strict follow up protocol, which included long term regular checkups after every three months. The patient was educated about the fact that due to loss of maxillary posteriors, she had developed a habit of bringing the mandible forward while mastication and this habit needed to be rectified. A demonstration on how to eat was given to the patient. After a period of 5 years the patient's prosthesis continues to be in a healthy state (Figure 7). Radiographs show no evidence of bone loss around the pier abutment (Figure 8).

\section{Discussion}

Dynamic occlusal examination in such cases is essential and it should foresee the current events that are taking place and what led to those events. In this case the wear facets on the canines are one such example. These wear facets had started developing only after the posterior maxillary teeth were lost. In case the wear facets are severe and the canines no longer disclude the posteriors, then the treatment plan include restoration of anterior guidance with crowns in relation to maxillary canines. The reason that canines were undergoing wear in this case was because of the posterior loss of the teeth due to which the tendency of the patient was to masticate with the lower teeth by bringing the mandible forward, a term what can be called as protrusive mastication. This collaborated with other findings in the examination of occlusion.

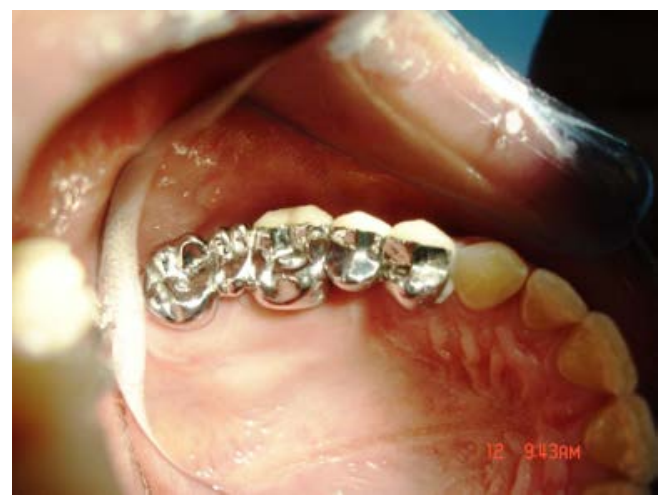

Figure 6. Fixed movable bridge in place with non-visible semi rigid connector
The need for stress breakers on a pier abutment which is supporting prosthesis on both ends is based on the fact that the vertical resilience of a normal, healthy tooth in its socket is approximately $0.1 \mathrm{~mm}$ to $0.2 \mathrm{~mm}$. Non Rigid Connector transfers shear stresses to supporting bone rather than concentrating them in connectors. It minimizes mesiodistal torquing of abutments and permits them to move independently. When incorporated in the mandibular pier abutment situation, it allows mandibular flexure during opening and closing movements. According to a study, [16] the stress distribution and values of a fixed partial denture and pier abutment are affected by the presence and location of a non-rigid connector. The area of minimum stress concentration occurs in pier abutments when a non-rigid connector is located in the distal region of the pier abutment for a 5 unit fixed partial denture with a pier abutment [17].

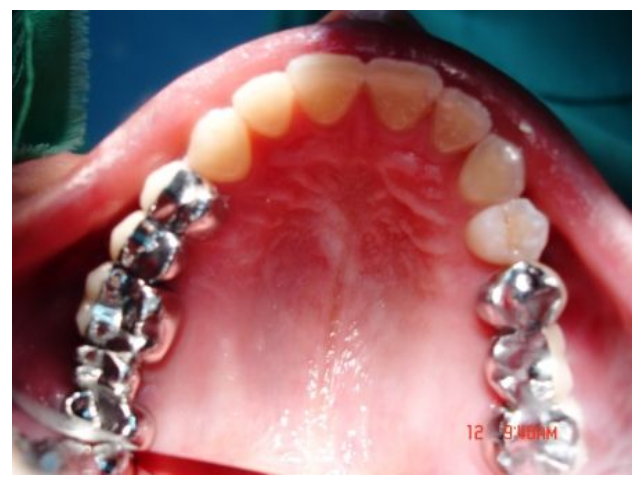

Figure 7. Fixed movable prosthesis after 5 years

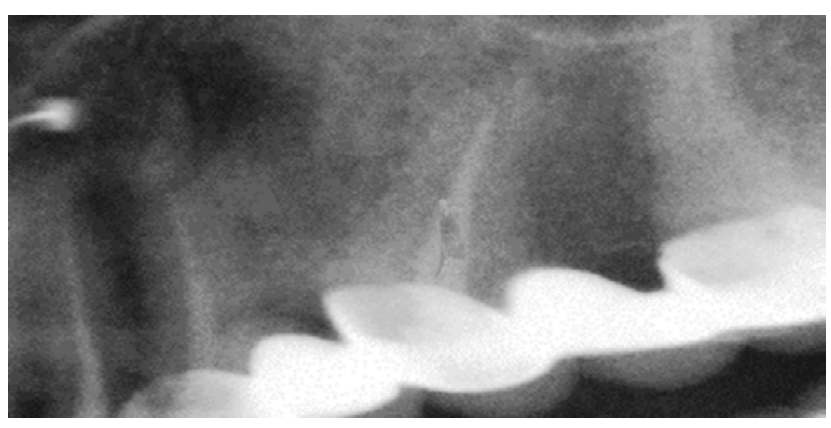

Figure 8. Post follow up radiographs

Russell D, et al [18] studied the stress transfer patterns with variable implant support and simulated natural teeth through rigid and non-rigid connection under simulated functional loads. They concluded that rigid connector in particular situations caused only slightly higher stresses in the supporting structure and demonstrated more widespread stress transfer. The choice of placing the nonrigid connector can still be debated on the fact that the nature of the underlying tooth and the length of the lever arm from the fulcrum should be taken into consideration. As in this case if the entire fixed, movable prosthesis is divided into an anterior segment and the posterior segment, then the posterior segments seem to have less vertical movements within the periodontal ligament because of the presence of wide divergent roots and less edentulous span. Moreover the presence of the non-rigid connector in the form of semi precision attachment also requires immaculate hygiene maintenance. The mesial side is easily accessible and therefore convenient for patients to practice non-conventional oral hygiene aids like 
interdental brushes. The efficiency of cleaning the area where contours are more prone to be altered definitely needs consideration if long term success is to be assured. In order to avoid the impact of fibrous foods between the two segments, an occlusal bevel was added to the semi precision attachment at the occlusal level. In order to prevent binding between the male and the female portion of the semi precision attachment the portion of the male part apical to the occlusal portion was relieved laterally. The tipping and /or unseating of the restoration were prevented by keeping the same length of the attachment parts [18].

With advances in resin cement technology, the current focus of fixed movable prosthesis has shifted from conventional to resin bonded fixed movable partial dentures [19].

\section{Conclusion}

Within the scope and limitation of this clinical report, it can be concluded that a fixed movable prosthesis is an ideal alternate choice to a cast partial denture in a partial edentulous situation where a pier abutment is located and that a custom made semi precision attachment can suffice the stress breaking effect necessary in a fixed movable prosthesis.

\section{Acknowledgement}

The authors would like to acknowledge Mr Sanawar Shuja and Mr Shahzad for their untiring help during the laboratory procedures of the treatment.

\section{References}

[1] Johnston JF, Phillips RW and Dykema RW. Modern Practice in Crown and Bridge Prosthodontics Ed. 2, Philadelphia 1965; W. B. Saunders Company:5-6.
[2] Wilson WH and Lang RL. Practical Crown and Bridge Prosthodontics, New York. 1962; McGraw-Hill Book Company, Inc: 85-86

[3] Shillingburg HT, Hobo S, Whitsett LD, Jacobi R, Brackett SE. Fundamentals of fixed prosthodontics. 3rd Ed. Chicago. Quintessence; 1997: 85-103

[4] Rosenstiel SF, Land MF, Fujimoto J. Contemporary fixed Prosthodontics. 3rd Ed. St. Louis: Elsevier; 2000: 46-64.

[5] Carr AB, McGivney GP, Brown DT. McCracken's removable partial Prosthodontics. 11th Ed. St. Louis: Elsevier; 2004: 189-229.

[6] Nyman SR, Lang NP. Tooth mobility and the biological rationale for splinting teeth. Periodontal 2000, 1994; 4: 15-22.

[7] Sorensen JA, Martinoff JT. Endodontically treated teeth as abutments. J Prosthet Dent 1985; 53: 631-636.

[8] Goodacre CJ, Spolnik KJ. The prosthodontic management of endodontically treated teeth: a literature review. Part I. Success and failure data, treatment concepts. J Prosthodont 1994; 3: 24350.

[9] Savion I, Saucier CL, Rues S, Sadan A, Blatz M. The pier abutment: a review of the literature and a suggested mathematical model. Quintessence Int. 2006 May; 37 (5): 345-352.

[10] Markley K. Broken-Stress 'Principle \& design in fixed bridge prosthesis. J Prosthet Dent 1951; 1: 416-423.

[11] Adams JD. Planning posterior bridges. J Am Dent Assoc 1956; 53:647-654.

[12] Standlee JP, Caputo AA. Load transfer by fixed partial denture with three abutments. Quintessence Int 1988; 19:403-410.

[13] Gill JR. Treatment planning for mouth rehabilitation. J Prosthet Dent 1952; 2: 230-45.

[14] Oruc S, Eraslan O, Tukay HA, Atay A. Stress analysis of effect of non-rigid connectors on fixed partial dentures with pier abutments. J Prosthet Dent 2008; 99: 185-92.

[15] Savion I, Saucier CL, Rues S, Sadan A, Blatz M. The pier abutment: A review of literature and suggested mathematical model. Quintessence Int 2006; 37: 345-52.

[16] Sutherland JK, Holland GA, Sluder TB, Whie JT. A Photoelastic stress analysis of stress distribution in bone supporting fixed partial dentures of rigid \& nonrigid designs. J Prosthet Dent 1980; 44: 616-23.

[17] Selcuk Oruc, Arzu Atay. Stress analysis of effects of nonrigid connectors on fixed partial dentures with pier abutments. J Prosthet Dent 2008; 99: 185-92.

[18] Russell D Nishimura, et al. Photoelastic stress analysis of load transfer to implants and natural teeth comparing rigid and semi rigid connectors. J Prosthet Dent 1999; 81: 696-703.

[19] Botelho MG, Dyson JE. Long-span, fixed-movable, resin-bonded fixed partial dentures: A retrospective, preliminary clinical investigation. Int J Prosthodont 2005; 18: 371-6. 